\title{
NOTES OF A CASE OF CERFBELLO-PONTINE CYST.
}

\author{
By GEORGE PEACOCKE, M.I)., F.R.C.P.I. ; \\ Assistant Physician Adelaide Hospital, Dublin.
}

[Read in the Section of Medicine, May 17. 1907.]

J. R., aged thirty years, a native of County Wicklow, was admitted to the Adelaide Hospital on March 4 under my care. He had been a coachman, but for some time past had assisted his father at farming work. He was in his usual good health up to five months ago, when he noticed that when walking along the road it seemed to him that instead of being a level surface it appeared to be in hills and hollows. This, he says, was the first symptem of any kind that he noticed. Shortly afterwards he began to suffer from headaches, the pain being felt in the back of his head and behind his eyes. The pain was always worse in the morning on waking up, was not continuous throughout the day, and did not disturb his sleep. His appetite was good, bowels fairly regular, and he had no vomiting. His sight had been getting bad for about three months, and he had also noticed that he was deaf in the left ear. His gait had become somewhat unsteady, which he attributed to giddiness. He had never met with any injury to his head, was a temperate man, and had not contracted syphilis.

On examination he appeared to be a strong, well-developed, muscular man. The thoracic and abdominal organs were healthy. His temperature and pulse were normal. His gait was rather unsteady, but not very markedly so, except when attempting to turn. Knee-jerks were normal; ankle clonus was not present; no loss of power or sensation in the legs or arms. On examining his face it was at once apparent that he had some degree of facial palsy. All the muscles supplied by the seventh nerve on the left side were affected, but the paralysis was not complete. He had 
Dr. Peacocke-Cerebello-pontine Cyst.

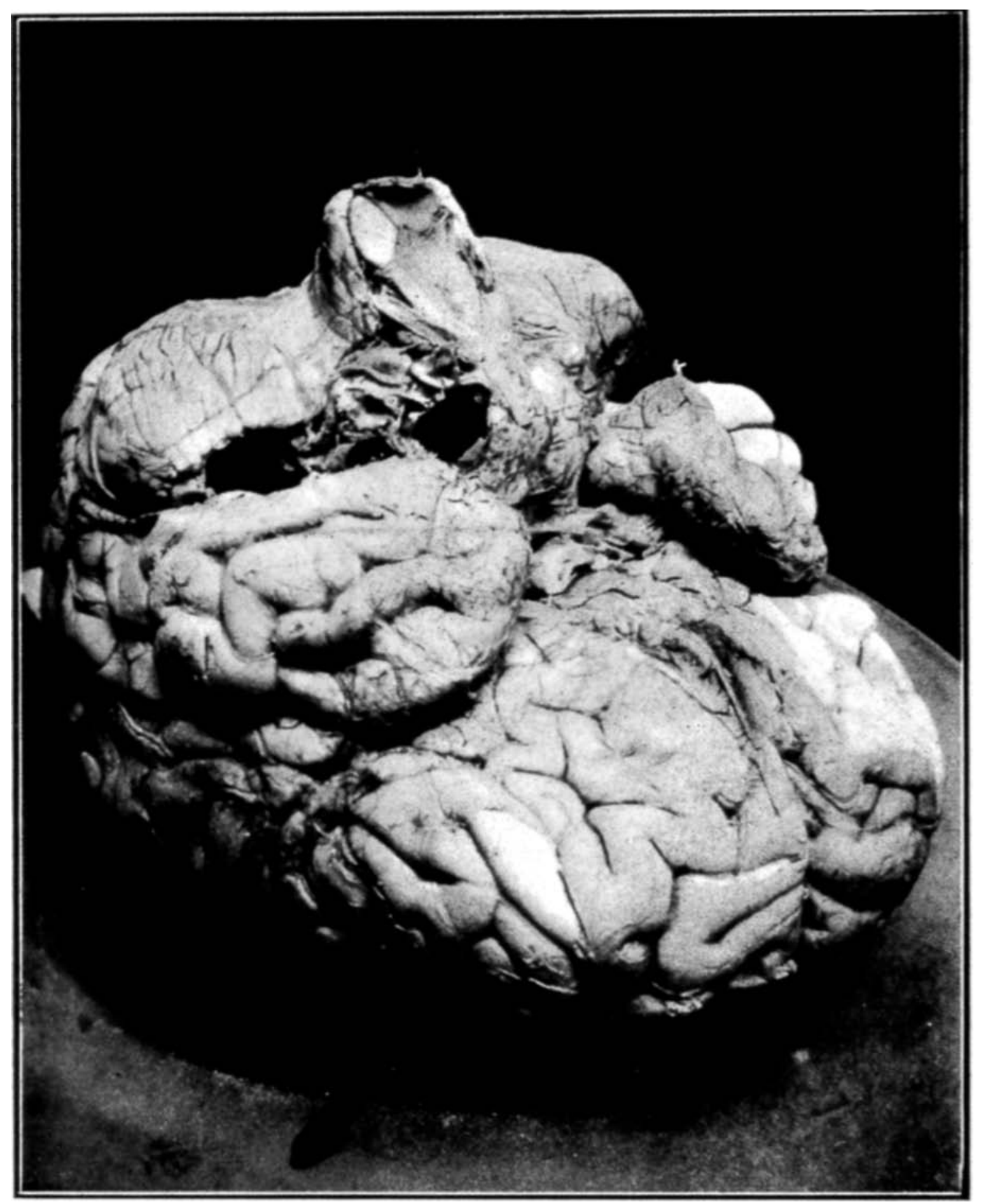

Firi. 1.--Shows Tongue like Processes of Cerebellum. 
no paralysis of any of the muscles of the eyeballs. Conjugate deviation of the eyes to the left caused a few jerky nystagmoid movements, but true nystagmus was not present. Sensation on the left side of the face was almost entirely lost. There did not appear to be any loss of taste.

Mr. Swanzy kindly examined his eyes and gave me the following report:---

“O. Sin. $\frac{6}{1 \frac{5}{2}}$ (partly)；O. Dex. $\frac{6}{6} \overline{0}$. In each eye optic neuritis, with small apoplexies and white patch in neighbourhood of optic disc."

As he complained of deafness of the left ear I asked Mr. Law to examine him, and he informed me that in the left ear Rinne's test was negative, but in the right ear positive. Weber's test was uncertain. Drums were normal, and there was no evidence of any suppurative condition in ear, sinuses or meninges.

The diagnosis made was a tumour on the left side of the brain, in the neighbourhood of the pons and cerebellum, involving the fifth, seventh and eighth nerves. The only classical symptom that was wanting to complete the picture was vomiting, and this was conspicuous by its absence throughout the whole course of the illness.

His condition remained very much the same for six weeks. The headache, which during all the time he was under observation was invariably referred to the frontal region and behind the eyes, became perhaps a little more severe, but seldom interfered with his sleep, and was not constant all dar. His appetite continued good, and his only complaint was that he did not feel himself getting any better. He was able to be out every fine dar in the grounds of the hospital.

On the morning of April 15. wheu I was examining him as he sat up in bed, he became pale and weak, but restoratives soon brought him round again, and he seemed none the worse afterwards.

At 6 a.m. on April 21 he had a similar attack, which soon passed off, but at 9 a.m. the same morning he died quite suddenly. The only treatment he received was $10 \mathrm{gr}$. doses of iodide of potash thrice daily, but this had been discontinued for ten days before his death. Three hours after death I injected about six ounces 
of 40 per cent. formalin saturated with common salt through the inner canthus of each eye, and the brain was removed thirty hours later.

On removal of the brain it was found that the lesion consisted of a cystic growth involving the pons and cerebellum on the left side. There was a small amount' of pale, straw-coloured fluid in this, but it unfortunately escaped in the removal of the brain, as the wall of the cyst was adherent to the bone, and became torn, and so prevented any examination of the fluid being made.

On making a horizontal section through the pons and cerebellum it was seen that the cyst was not a single cavity. A thin layer of membrane separated the larger cerebellar cyst from that involving the pons. Between these two there was a triangular bridge of tissue, somewhat cheesy in appearance, and in it was a small, round cyst containing some blood.

In the photographs, kindly taken for me by Professor Scott, you will observe the two tongue-like processes of cerebellum proceeding downwards over the medulla. I do not remember ever seeing a similar condition.

Dr. Harrey kindly made sertions from the small triangular area I have mentioned, and he has furnished me with the following report:

"Section of a piece of the brain tissue adjoining the cysts shows two different tissues.

"(1.) Composed of spindle-shaped elements, very cellular and resembling in all respects a spindle-celled sarcoma.

"(2.) A tissue composed of smaller cells (neuroglial)."

The absence of vomiting and of all symptoms referable to pressure on the pons, except those resulting from involvement of the fifth, seventh, and eighth nerves, seem points of interest in the case.

Simple cysts of the cerebellum are not common. Most of the so-called cerebellar cysts are merely cystic degeneration of tumours, and, as Williamson points out, a cerebellar cyst can only be classed as simple or serous 
when minute examination shows no trace of hydatid disease, cysticercus, hæmorrhage, or tumour.

The histological examination suggests that this was originally a tumour composed of glio-sarcomatous tissue which had undergone cystic degeneration.

Dr. Parsons said that hardly any cases were more trying than brain cases, and he desired to know if the question of operative interference had been raised. If the surgeon had been able to strike the cyst, the eyesight might have been saved.

Dr. CraIg instanced a case in which loss of hearing gave a fair opportunity of localising the tumour, but the operation failed, and the girl died.

Dr. Moorhead said the question raised by Dr. Parsons was very important. In cases where localising symptoms made the position certain, he thought that early operation should be recommended.

Dr. Peacocke, in reply, said that the question of operation did suggest itself to him, but no one else who saw the case suggested it. 